\title{
Growth of ZnO Nanorod Film on Glass Substrate by Nitric Acid Assisted Aqueous Solution Deposition
}

\author{
Ming-Kwei Lee, Mu-Kai Wang, Hao-Yu Wang, Chang-Chin Tsai, Cheng-Yu Kung, Chia-En Yang, \\ Huan-Chi Lung \\ Department of Electronic Engineering, Chung Yuan Christian University \\ 200 Chung-Pei Rd., Chung Li, 32023 Taiwan, R. O. C. \\ mklee@cycu.edu.tw; rgps8297@ hotmail.com; wanghow01@gmail.com; g10476005@cycu.edu.tw \\ nene05050407@gmail.com; yang455121@hotmail.com; showmylife09@gmail.com
}

\begin{abstract}
In this paper, the growth of $\mathrm{ZnO}$ nanorod film transformed from $\mathrm{ZnO}$ nanorod array on glass substrate was investigated. $\mathrm{ZnO}$ seed layer was first prepared on substrate by RF sputtering. Zinc nitrate and hexamethylenetetramine were used as precursors for the growth of $\mathrm{ZnO}$ nanorod array on glass substrate at $50{ }^{\circ} \mathrm{C}$. The aqueous solution was assisted with the incorporation of nitric acid to increase the growth rate and the grain size of $\mathrm{ZnO}$ nanorod. With the growth time, $\mathrm{ZnO}$ nanorod film is gradually transformed from $\mathrm{ZnO}$ nanorod array.
\end{abstract}

Keywords: $\mathrm{ZnO}$, nanorod, film, glass, ASD

\section{Introduction}

$\mathrm{ZnO}$ is a promising material for electronic devices from its wide direct band gap of $3.37 \mathrm{eV}$ and high exciton binding energy of $60 \mathrm{meV}$ at room temperature and has been extensively studied because of its potential applications in various fields, such as gas sensors, solar cells, photodetectors, light emitting diodes, field effect transistors, and etc [1-5]. The preparation of high quality $\mathrm{ZnO}$ film is a fundamental work for those applications. There are many techniques for the preparation of $\mathrm{ZnO}$ films, such as pulsed laser deposition [6], chemical vapor deposition [7], spray pyrolysis [8], sol-gel process [9] and etc.

The aqueous solution deposition (ASD) has many advantages, for example very low growth temperature, unlimited growth area, cheap and simple process, and suitable for mass production. Recently, the ASD method was used for the growth of single crystalline $\mathrm{ZnO}$ nanorod array with excellent optical characteristics on various substrates [10], [11]. It is expected that high quality $\mathrm{ZnO}$ nanorod film can be transformed from single crystalline nanorod array by extending the growth time.

Generally, the glass substrate for ASD-ZnO film has many advantages such as transparent and low cost, but the growth rate is quite low and the transformation into film is difficult on amorphous glass substrate. Nitric acid (HNO3) is a strong acid and can modulate the concentrations of $\mathrm{Zn} 2+$ ions and hence control the $\mathrm{ZnO}$ growth. In this report, the characteristics of $\mathrm{ZnO}$ nanorod film transformed from $\mathrm{ZnO}$ nanorod array on glass substrate by HNO3 assisted ASD were investigated.

\section{Experimental}

$\mathrm{ZnO}$ nanorod array was grown on glass substrate with a sputtered $\mathrm{ZnO}$ seed layer by aqueous solution deposition. A $\mathrm{ZnO}$ seed layer with the thickness of about $100 \mathrm{~nm}$ was prepared by RF sputtering on glass substrate. ZnO with the purity of $99.99 \%$ was used as the target. The argon flow rate and the RF power were kept at $35 \mathrm{sccm}$ and $60 \mathrm{~W}$, respectively. The aqueous solutions of $0.1 \mathrm{M}$ zinc nitrate $\left(\mathrm{Zn}\left(\mathrm{NO}_{3}\right)_{2}\right) 30 \mathrm{ml}$ and $0.1 \mathrm{M}$ hexamethylenetetramine $\left(\mathrm{C}_{6} \mathrm{H}_{12} \mathrm{~N}_{4}\right.$, HMT) $30 \mathrm{ml}$ were used as precursors for the growth of $\mathrm{ZnO}$ nanorod arrays at $50{ }^{\circ} \mathrm{C}$. In order to prevent the $\mathrm{ZnO}$ precipitates falling on the substrate, the substrate was held upside down to avoid $\mathrm{ZnO}$ precipitates falling on $\mathrm{ZnO}$ nanorod array. For $\mathrm{HNO}_{3}$ assisted ASD-ZnO growth, $0.05 \mathrm{M} \mathrm{HNO}_{3} 1 \mathrm{ml}$ was used. The preparation conditions for $\mathrm{ZnO}$ nanorod film are the same as those 
for $\mathrm{ZnO}$ nanorod array except longer growth time. The electron mobility was examined by Van der Pauw Hall measurement.

\section{Result and discussion}

The morphology of $\mathrm{ZnO}$ nanorod film was observed by field-emission scanning electron microscopy (FE-SEM). Figure 1 (a) and (b) show SEM top views of ASD-ZnO nanorod films grown on glass substrates for 12 and $36 \mathrm{hrs}$ at $50^{\circ} \mathrm{C}$. A continuous and smooth film is hard to be obtained and it is not suitable for TFT fabrication.

Figure 2 (a) and (b) show the SEM top views of HNO3 assisted ASD-ZnO nanorod films grown on glass substrates for the growth time of 12 and $36 \mathrm{hrs}$ at $50^{\circ} \mathrm{C}$ with the incorporation of $0.05 \mathrm{M} \mathrm{HNO} 31 \mathrm{ml}$, respectively. We can observe that the diameter of $\mathrm{ZnO}$ nanorod is increased and the $\mathrm{ZnO}$ nanorod film transformed from $\mathrm{ZnO}$ nanorod array is apparently improved on $\mathrm{ZnO}$ sputtered glass substrate.
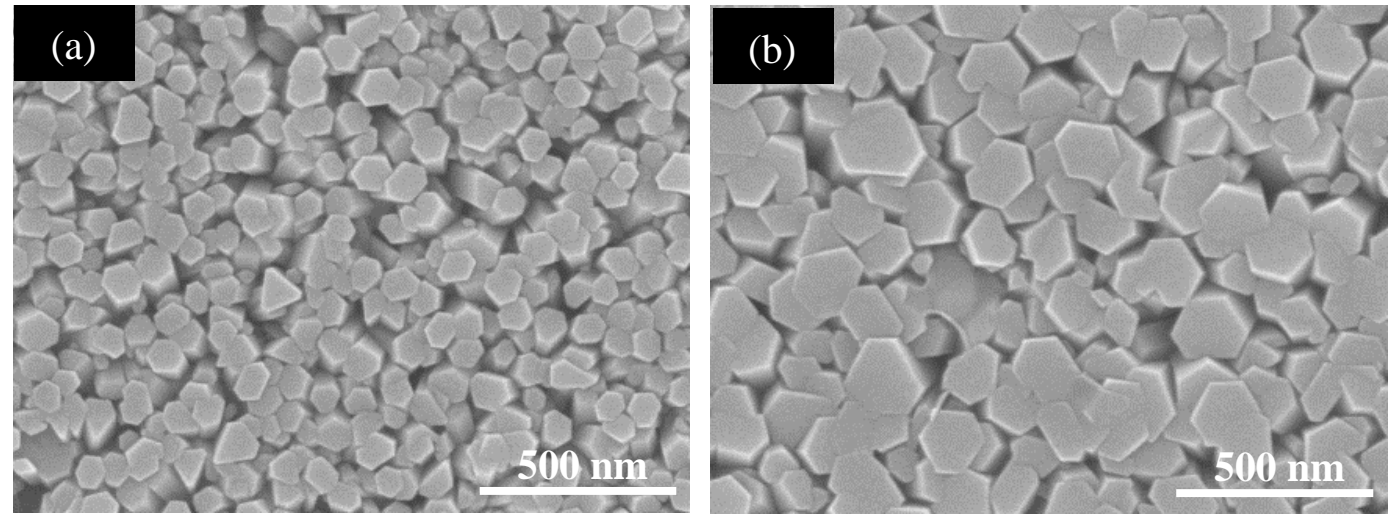

Fig. 1: Top views of ASD-ZnO nanorod films grown on glass substrates for (a) 12 and (b) $36 \mathrm{hrs}$ at $50^{\circ} \mathrm{C}$.
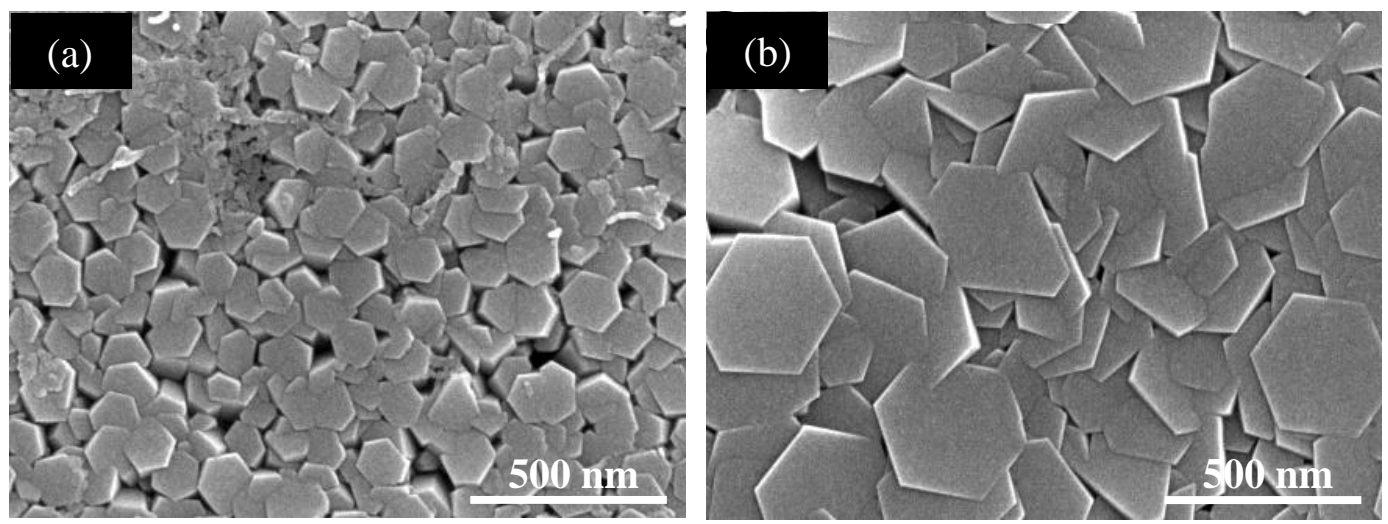

Fig. 2: Top views of $\mathrm{HNO}_{3}$ assisted ASD-ZnO nanorod films grown on glass substrates for (a) 12 and (b) $36 \mathrm{hrs}$ at $50^{\circ} \mathrm{C}$.

Figure 3 shows the grain size as a function of the growth time for conventional and HNO3 assisted ASD-ZnO nanorod films. The growth rate of $\mathrm{HNO} 3$ assisted ASD-ZnO nanorod film is much enhanced. It could be strongly associated by $\mathrm{Zn} 2+$ from HNO3 incorporation [12]. Moreover, the HNO3 assisted ASD-ZnO nanorod film exhibits electron Hall mobility of $1.25 \mathrm{~cm} 2 / \mathrm{V}$-s for the growth time of $12 \mathrm{hrs}$ and $2 \mathrm{~cm} 2 / \mathrm{V}$-s for the growth time of $36 \mathrm{hrs}$.

Figure 4 shows micro-PL spectra of ASD-ZnO nanorod films grown at $50{ }^{\circ} \mathrm{C}$ for $36 \mathrm{hrs}$ with the incorporation of $\mathrm{HNO} 3$ before and after thermal annealing in $\mathrm{N} 2 \mathrm{O}$ at $300^{\circ} \mathrm{C}$ for $1 \mathrm{hr}$. The PL spectrum of as-grown $\mathrm{ZnO}$ nanorod film has two main emission peaks. The peak at $380 \mathrm{~nm}(3.26 \mathrm{eV})$ is from the near-bandgap emission and the broadband emission centered at about $580 \mathrm{~nm}$ is associated with impurities or intrinsic defects [11]. After thermal annealing, the near-bandgap emission increases and the broadband emission decreases from $\mathrm{OH}$ out-gassing and crystalline improvement. 


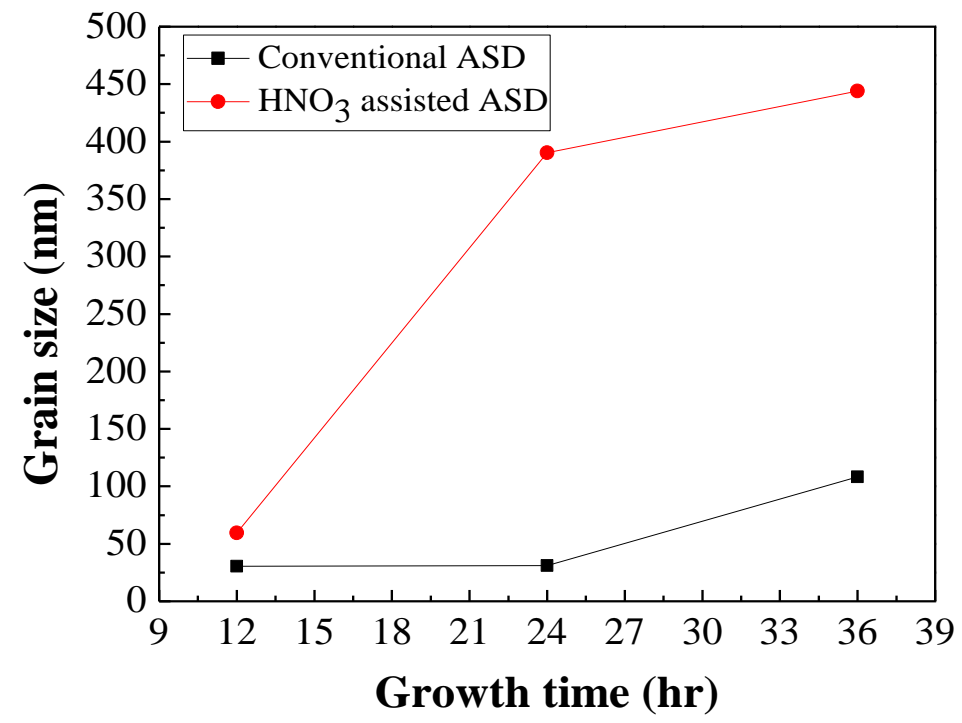

Fig. 3: Grain sizes of conventional and $\mathrm{HNO}_{3}$ assisted ASD-ZnO nanorod films as a function of the growth time.

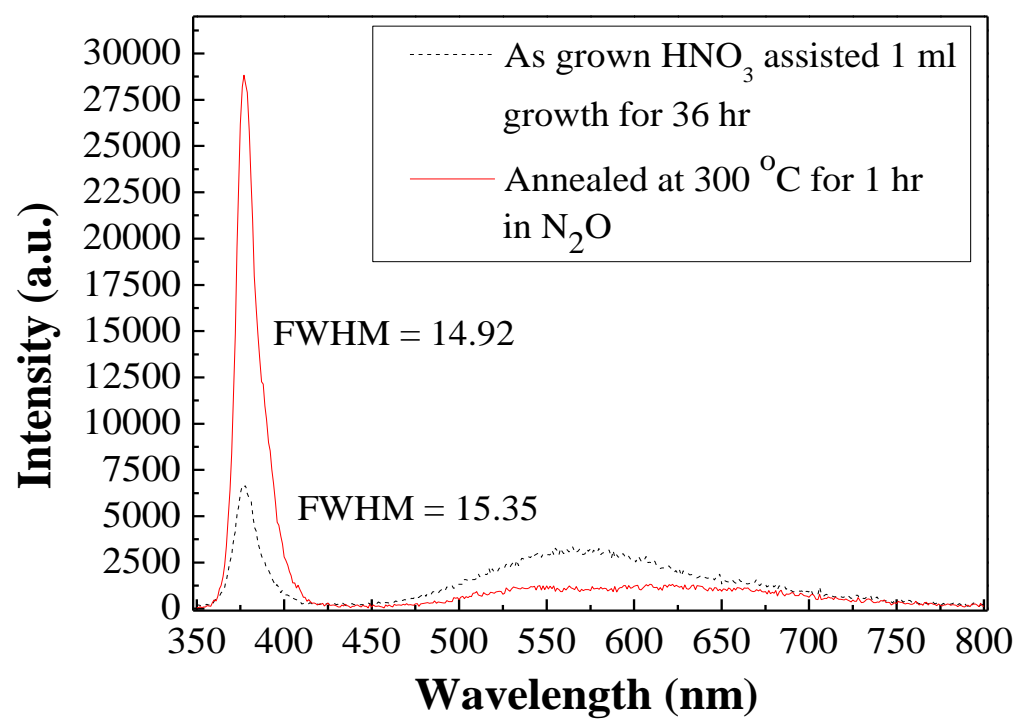

Fig. 4: Micro-PL spectra of as-grown and thermal annealed $\mathrm{HNO}_{3}$ assisted ASD-ZnO nanorod films grown for 36 hrs.

\section{Conclusion}

In this report, the growth of $\mathrm{ZnO}$ nanorod film transformed from $\mathrm{ZnO}$ nanorod array on glass substrate was investigated. Zinc nitrate and HMT were used as precursors for the growth of $\mathrm{ZnO}$ nanorod array at $50{ }^{\circ} \mathrm{C}$. Nitric acid plays an important role for the improvement of $\mathrm{ZnO}$ nanorod film quality. The quality of $\mathrm{ZnO}$ nanorod film can be improved by thermal annealing in $\mathrm{N}_{2} \mathrm{O}$ ambient. The electron mobility of $\mathrm{ZnO}$ nanorod film on glass substrate can reach $2 \mathrm{~cm}^{2} / \mathrm{V}$-s examined by Van der Pauw Hall measurement.

\section{Acknowledgements}

The authors would like to thank the National Science Council of Republic of China for their support under contract No. 104-2221-E-033-030-MY2. 


\section{References}

[1] R. Kumar, O. Al-Dossary, G. Kumar and A. Umar, "Zinc Oxide Nanostructures for $\mathrm{NO}_{2}$ Gas-Sensor Applications: A Review," Nano-Micro Lett, vol.7,no. 2, pp. 97-120, 2015.

[2] J. Kim, G. Kim, T. K. Kim, S. Kwon, H. Back, J. Lee, S. H. Lee, H. Kang and K. Lee, "Efficient planarheterojunction perovskite solar cells achieved via interfacial modification of a sol-gel $\mathrm{ZnO}$ electron collection layer," J. Mater. Chem. A, vol. 2, no. 41, pp. 17291-17296, 2014.

[3] Y. Hou, Z. Mei and X. Du, "Semiconductor ultraviolet photodetectors based on $\mathrm{ZnO}$ and $\mathrm{Mg}_{\mathrm{x}} \mathrm{Zn}_{1-\mathrm{x}} \mathrm{O}$," J. Phys. D: Appl. Phys., vol. 47, no. 28, pp. 283001-1-283001-25, 2014.

[4] H. Jeong, D. J. Park, H. S. Lee, Y. H. Ko, J. S. Yu, S. B. Choi, D. S. Lee, E. K. Suh, and M. S. Jeong, "Lightextraction enhancement of a GaN-based LED covered with ZnO nanorod arrays," Nanoscale, vol.6, no. 8, pp. 43714378, 2014.

[5] A. Sharma, C. Madhu, and J. Singh, "Performance Evaluation of Thin Film Transistors: History, Technology Development and Comparison: A Review," Int. J. Comput. Appl., vol. 89, no. 15, pp. 36-40, 2014.

[6] M. G. Tsoutsouva, C. N. Panagopoulos, D. Papadimitriou, I. Fasaki, and M. Kompitsas, "ZnO thin films prepared by pulsed laser deposition," Mater. Sci. Eng. B, vol. 176, no. 6, pp. 480-483, 2011.

[7] J. Yang, Y. Pei, R. Hu, B. Fan, C. Tong, T. Kojima, Z. Wu, H. Jiang, and G. Wang, "Morphology controlled synthesis of crystalline $\mathrm{ZnO}$ film by MOCVD: from hexagon to rhombus," Cryst. Eng. Comm., vol. 14, no. 24, pp. 8345-8348, 2012.

[8] N. Lehraki, M. S. Aida, S. Abed, N. Attaf, A. Attaf, and M. Poulain, "ZnO thin films deposition by spray pyrolysis: Influence of precursor solution properties," Curr. Appl. Phys., vol. 12, no. 5, pp. 1283-1287, 2012.

[9] K. L. Foo, U. Hashim, K. Muhammad, and C. H. Voon, "Sol-gel synthesized zinc oxide nanorods and their structural and optical investigation for optoelectronic application," Nanoscale Res. Lett., vol. 9, no. 56, pp. 429-1429-10, 2014.

[10] L. Vayssieres, "Growth of arrayed nanorods and nanowires of $\mathrm{ZnO}$ from aqueous solutions," Adv. Mater., vol. 15, no. 5, pp. 464-466, 2003.

[11] H. Q. Le, S. J. Chua, Y. W. Koh, K. P. Loh, Z. Chen, C. V. Thompson, and E. A. Fitzgerald, "Growth of single crystal $\mathrm{ZnO}$ nanorods on GaN using an aqueous solution method," Appl. Phys. Lett., vol. 87, no. 10, pp. 101908$1101908,2005$.

[12] G. Amin, M. H. Asif, A. Zainelabdin, S. Zaman, O. Nur, and M. Willander, "Influence of pH, Precursor Concentration, Growth Time, and Temperature on the Morphology of $\mathrm{ZnO}$ Nanostructures Grown by the Hydrothermal Method," J. Nanomater, vol. 2011, pp. 1-9, 2011. 